\title{
Effect of Fungicide and Timing of Application on Soybean Rust Severity and Yield
}

\author{
T. A. Mueller, Department of Crop Sciences, University of Illinois, Urbana, IL 61801; M. R. Miles, USDA-ARS, \\ National Soybean Research Center, Urbana, IL 61801; W. Morel, Ministerio de Agricultura y Ganadería, Centro \\ Regional de Investigación Agrícola (CRIA), Capitán Miranda, Itapúa, Paraguay; J. J. Marois, Department of Plant \\ Pathology, and D. L. Wright, Department of Agronomy, University of Florida - North Florida Research and Educa- \\ tion Center, Quincy, FL; R. C. Kemerait, Department of Plant Pathology, University of Georgia, Tifton, GA; \\ C. Levy, Commercial Farmers Union of Zimbabwe, Harare, Zimbabwe; and G. L. Hartman, USDA-ARS, Depart- \\ ment of Crop Sciences, National Soybean Research Center, University of Illinois, Urbana, IL 61801
}

\begin{abstract}
Mueller, T. A., Miles, M. R., Morel, W., Marois, J. J., Wright, D. L., Kemerait, R. C., Levy, C., and Hartman, G. L. 2009. Effect of fungicide and timing of application on soybean rust severity and yield. Plant Dis. 93:243-248.

Soybean rust, caused by Phakopsora pachyrhizi, is a devastating foliar disease of soybean that may cause significant yield losses if not managed by well-timed fungicide applications. To determine the effect of fungicide timing on soybean rust severity and soybean yield, field trials were completed in Paraguay (four locations), the United States (two locations), and Zimbabwe (one location) from 2005 to 2006. Treatments at each location included applications of tebuconazole, pyraclostrobin, or a combination of azoxystrobin + propiconazole, and in some locations pyraclostrobin + tebuconazole at the following soybean growth stages (GS): (i) GS R1 (beginning flowering), (ii) GS R3 (beginning pod), (iii) GS R5 (beginning seed), (iv) GS R1 + R3, (v) GS R3 + R5, and (vi) GS R1 + R3 + R5. Soybean yields from plots treated with fungicides were 16 to $114 \%$ greater than yields from no fungicide control plots in four locations in Paraguay, 12 to $55 \%$ greater in two locations in the United States, and $31 \%$ greater in Zimbabwe. In all locations, rust severity measured over time as area under the disease progress curve (AUDPC) was negatively correlated $(r=-0.3, P<0.0001)$ to yield. The effectiveness of any given treatment (timing of application and product applied) was often dependent on when rust was first detected and the intensity of its development. For example, when soybean rust was first observed before GS R3 (two locations in Paraguay), the plants in plots treated with a fungicide at GS R1 had the lowest AUPDC values and highest yields. When soybean rust was first observed after GS R3, plants treated with a fungicide at GS R3 and/or GS R5 had the lowest AUDPC values and highest yields with a few exceptions.
\end{abstract}

Soybean rust, caused by the fungus Phakopsora pachyrhizi, is a devastating foliar disease of soybean. Soybean yield losses up to $80 \%$ in experimental trials have been reported in Asia $(8,17)$. Yield losses have been more recently reported from Paraguay in 2001 (as high as 60\%) (18), Brazil in 2003 (losses of 63\%) (18), and South Africa in 2001 (up to 100\%) (4). Reports of yield losses in the United States have not yet been as high as losses reported from other countries, but a 19\% loss

Corresponding author: G. L. Hartman

E-mail: ghartman@uiuc.edu

Trade and manufacturers' names are necessary to report factually on available data; however, the USDA neither guarantees nor warrants the standard of the product, and the use of the name by USDA implies no approval of the product to the exclusion of others that may also be suitable.

Accepted for publication 13 November 2008.

doi:10.1094/PDIS-93-3-0243

This article is in the public domain and not copyrightable. It may be freely reprinted with customary crediting of the source. The American Phytopathological Society, 2009. on average was reported in experimental plots in Alabama (5), and losses of up to 27 and $35 \%$ were reported based on experimental plots in Attapulgus, GA and Quincy, FL, respectively $(14,15)$.

Currently, there are no known commercial cultivars in the United States that are resistant to soybean rust. The first line of soybean rust management is to apply fungicides. If soybean rust becomes widespread in the United States, millions of soybean hectares may need to be sprayed with fungicides. Although fungicides have been reported to effectively control rust $(10,13,18)$, the cost of fungicides, fungicide applications, and potential yield losses due to improper application timings may all incur new costs to the soybean industry. The classes of fungicides currently recommended for the control of soybean rust include triazoles and strobilurins, but fungicides within these classes vary in their efficacy to control soybean rust (13).

Timing of foliar fungicide applications often is the key factor that determines success or failure to control fungal plant pathogens. For soybean, fungicide timing has been shown to be critical for the control of some foliar diseases. For example, the control of frogeye leaf spot of soybean (Cercospora sojina) varied with applications of benomyl at different reproductive growth stages of the crop (1). To manage soybean rust with fungicides, three strategies include applying fungicides in a predetermined calendar-based schedule $(10,12,13,18)$, scouting and applying fungicide after first detection of soybean rust, or utilizing a forecast system that monitors disease development in areas that are potential inoculum sources and applying fungicides ahead of a predicted deposition of spores. A calendar-based program with two or three applications provides the greatest level of yield protection; the crop is protected from flowering through grain fill; however, this may result in unnecessary fungicide applications that increase production costs and may have unforeseen consequences due to activity on nontarget fungi. The objectives of this study were to compare the effects of strobilurins, triazoles, and combination products, and the timing of their application based on the reproductive growth stage of the crop, on soybean rust severity and yield.

\section{MATERIALS AND METHODS}

Locations. Experiments were located at sites with prior reports of soybean rust. In 2005, there was one location in Paraguay (Bella Vista). In 2006, there were three locations in Paraguay (Bella Vista, Capitán Meza, and Pirapo), one in Zimbabwe (Enterprise), and two in the United States (Quincy, FL and Attapulgus, GA). At each location, a cultivar susceptible to soybean rust of appropriate maturity for the location was planted. The location, planting date, fungicide application dates, harvest dates, and plot dimensions for each location varied (Table 1). Except for foliar fungicide applications, locations were managed to achieve high yields using established best management practices. At the end of the season, the center two rows of each plot were harvested mechanically. The seed moisture was taken and the seed weight and yield were adjusted to $13 \%$ moisture.

Experimental design and treatments. The fungicides were selected to represent the strobilurin and triazole fungicide classes and a manufactured premix of stro- 
bilurin + triazole classes, and were applied within the labeled rates recommended by the manufacturer. At each location, the experiments were in a randomized complete block design with four blocks containing either 16 or 24 treatments. Bella Vista in 2005 and Georgia in 2006 had 16 treatments, while all of the other locations had 24 treatments. All locations had treatments of azoxystrobin (AZO) + propiconazole (PRO) (Quilt, Syngenta Crop Protection, Greensboro, NC) applied at growth stage (GS) R1 (beginning flowering), R3 (beginning pod), R5 (beginning seed), R1 + R3, and R3 + R5; pyraclostrobin (PYR) (Headline, BASF, Florham Park, NJ) applied at GS R1, R3, and R5; tebuconazole (TEB) (Folicur, Bayer CropScience, Research Triangle Park, NC) applied at GS R1, R3, R5, R1 + R3, and R3 + R5 (6). For sequential applications, when TEB was the first application, PYR was the second application (TEB/PYR), and when PYR was the first application, TEB was the second application (PYR/TEB). The additional treatments beyond the 16 were multiple applications of TEB, applied at GS R1 + R3, R3 + R5, and R1 + R3 + R5 and PYR + TEB applied at GS R1, R3, R5, $\mathrm{R} 1+\mathrm{R} 3$, and R3 + R5.

Fungicide application. In Paraguay, fungicides were applied with a $\mathrm{CO}_{2}$ powered backpack sprayer (Model GS or similar model, R\&D Sprayers, Opelousas, LA) with $1.5-\mathrm{m}$ boom equipped with four nozzle tips spaced $0.51 \mathrm{~m}$ apart. In Paraguay, TeeJet XR8002 (Spraying Systems Co., Wheaton, IL) flat fan nozzle tips were used. In Zimbabwe, a backpack sprayer with a single Lurmark F110/1.6/3 flood-jet nozzle tip (Lurmark Ltd., Cambridgeshire, UK) was used. In Florida, a platform sprayer, manufactured at the North Florida Research and Education Center in Quincy, powered by $\mathrm{CO}_{2}$ was used with Turbo TeeJet TT11002 (Spraying Systems Co.) flat fan nozzle tips spaced $0.46 \mathrm{~m}$ apart. In Georgia, a Spider Spray Trac Boom Sprayer (Lee Company, Idalou, TX) was used with TeeJet XR 11002 (Spraying Systems Co.) flat fan nozzle tips spaced $0.51 \mathrm{~m}$ apart. For all locations, a spray pressure of approximately 30 psi and 140 liters of water per hectare were used.

Disease assessment. In all locations, a visual soybean rust assessment was used on a plot basis by assessing the occurrence of rust and associated chlorosis within the canopy. In Paraguay in 2005, and in Florida and Georgia, plot severity was based on a scale from 0 to 5 in which a rating of $0=$ no disease, $1=$ low disease severity ( 1 to $10 \%$ of leaf area affected), $2=$ mediumlow disease severity $(10$ to $25 \%), 3=$ medium disease severity (25 to $50 \%$ ), $4=$ medium-high disease severity (50 to $75 \%$ ), and $5=$ high disease severity ( 75 to $100 \%$ ). The midpoint value of each rating range was used to convert the rating to a percent. In Zimbabwe, plot severity was based on a continuous scale from 0 to $100 \%$. In the second year in Paraguay, plot severity was recorded on a 0 to 9 scale where $0=$ no disease, $1=0.25 \%$ of leaf area affected, 2 $=0.5 \%, 3=1 \%, 4=2.5 \%, 5=5 \%, 6=$ $10 \%, 7=20 \%, 8=30 \%$, and $9=50 \%$. The area under disease progress curve (AUDPC) was calculated for treatments at each location to express the amount of disease over time (16). At most locations, rust was assessed at least three times between flowering (GS R1) and seed set (GS R5). The defoliation rating was a visual assessment on a continuous scale from 0 to $100 \%$ and was recorded when the unsprayed control exceeded 50\% defoliation.

Statistical analysis. Data were analyzed separately by location due to differences in soybean production practices and onset and severity of soybean rust. Analysis of variance (ANOVA) was used in the general linear models procedure (PROC GLM) of SAS 9.1 (SAS Institute, Cary, NC). Fisher's protected least significant differences test was used to compare means, where $\alpha=0.05$. A Pearson's correlation coefficient was used to evaluate relations among (i) AUDPC, (ii) defoliation, and (iii) yield at each location using the SAS correlation procedure (PROC CORR).

\section{RESULTS}

Locations with 16 treatments. Based on the ANOVA, treatment had a significant effect on AUDPC, defoliation, and yield (Table 2). At Bella Vista (2005), soybean rust was first observed at GS R5 after all fungicide treatments were completed. AUDPC differed among treatments, with the no fungicide control (NFC) having the greatest value (Table 3). All treatments with an application of TEB, regardless of application time or mixture with other fungicides, resulted in lower AUDPC values than all other treatments. Defoliation differed by treatment, with all treatments except for $\mathrm{AZO}+\mathrm{PRO}$ applied at GS R1 causing lower defoliation than the NFC. All plots treated with fungicides produced higher yields than the NFC, but not all had equal yields to the best treatment $(\mathrm{AZO}+\mathrm{PRO}$ at GS R3). AUDPC correlated ( $r=0.38, P=$ $0.0019)$ to defoliation and defoliation correlated $(r=-0.46, P<0.0001)$ to yield.

At Attapulgus, soybean rust was first observed at GS R4 before the GS R5 fungicide treatments were applied. AUDPC differed among treatments (Table 3), and all treatments resulted in lower AUPDC than the NFC. Of the eight treatments that resulted in the lowest AUDPC values, five were multiple fungicide applications and three were single applications (one at GS R3 and two at GS R5). Defoliation differed among treatments. Seven treatments did not differ from the treatment with the lowest defoliation (PYR/TEB at GS R1 + R3), with five of the seven having multiple applications, while two treatments (PYR at GS R1 and AZO + PRO at GS R5) did not differ from the NFC. Yield differed among treatments; all treatments except one, PYR at GS R5, resulted in a higher yield than the NFC. Ten treatments did not differ from the highest yielding treatment of PYR/TEB at GS R3 + R5. AUDPC and defoliation $(r=0.67, P<0.0001)$, AUDPC and yield $(r=-0.45, P=0.0002)$, and defoliation and yield $(r=-0.46, P=$ $0.0002)$ were correlated.

Locations with 24 treatments. Based on the ANOVA, treatment had a significant effect on AUDPC, defoliation, and yield (Table 2). At Bella Vista in 2006, soybean rust was first observed at GS R5 after all fungicide treatments were completed. All

Table 1. Field locations and experimental plot details used for fungicide application timing experiments for the control of soybean rust

\begin{tabular}{|c|c|c|c|c|c|c|c|c|c|c|}
\hline \multirow[b]{3}{*}{ Location $^{b}$} & \multirow{3}{*}{$\begin{array}{l}\text { Planting } \\
\text { date }\end{array}$} & \multirow[b]{3}{*}{ Soybean cultivar } & \multicolumn{5}{|c|}{ Days after planting } & \multirow{3}{*}{$\begin{array}{c}\text { Row } \\
\text { spacing } \\
(\mathrm{cm})\end{array}$} & \multirow{3}{*}{$\begin{array}{c}\text { Plot } \\
\text { length } \\
(\mathbf{m})\end{array}$} & \multirow{3}{*}{$\begin{array}{c}\text { Harvest } \\
\text { length } \\
(\mathrm{m})\end{array}$} \\
\hline & & & \multicolumn{3}{|c|}{ Fungicide applicationa $^{a}$} & \multirow{2}{*}{$\begin{array}{c}\text { 1st detect. } \\
\text { of rust }\end{array}$} & \multirow[b]{2}{*}{ Harvest } & & & \\
\hline & & & GS R1 & GS R3 & GS R5 & & & & & \\
\hline Bella Vista, Paraguay & 23 Dec 04 & Asgrow A8000 & 55 & 81 & 102 & 102 & 151 & 40 & 10 & 8 \\
\hline Bella Vista, Paraguay & 12 Nov 05 & Asgrow A8000 & 69 & 88 & 102 & 102 & 151 & 40 & 8 & 6 \\
\hline Enterprise, Zimbabwe & 10 Dec 05 & SC Siesta & 55 & 70 & 85 & 85 & 147 & 76 & 6 & 6 \\
\hline Capitán Meza, Paraguay & 10 Jan 06 & NA 9000 & 64 & 87 & 107 & 67 & 126 & 40 & 8 & 6 \\
\hline Pirapo, Paraguay & 7 Feb 06 & NA 8500 & 52 & 72 & 92 & 56 & 121 & 40 & 8 & 6 \\
\hline Quincy, FL & 31 May 06 & DeKalb H7242RR & 56 & 77 & 97 & 88 & 154 & 91 & 8 & 8 \\
\hline Attapulgus, GA & 31 May 06 & Asgrow AS758RR & 58 & 79 & 102 & 93 & 173 & 91 & 11 & 11 \\
\hline
\end{tabular}

a GS = growth stage, R1 = first flower, R3 = initial pod development, R5 = initial seed development, and DAP = days after planting to fungicide application or harvest.

b Zimbabwe location was the Rattray Arnold Research Station, Florida was the University of Florida, North Florida Research and Education Center at Quincy, and Georgia was the University of Georgia research station at Attapulgus. 
treatments resulted in lower AUDPC values than the NFC, even though the disease pressure was low (Table 4). Defoliation differed among treatments, and 9 of 23 treatments resulted in less defoliation than the NFC. Six of these treatments were multiple applications that included TEB. Six treatments produced higher yields than the NFC: TEB at GS R3 + R5, PYR + TEB at GS R1 + R3, PYR + TEB at GS $\mathrm{R} 3$ + R5, PYR/TEB at GS R1 + R3, PYR/TEB at GS R3 + R5, and TEB/PYR at GS R3 + R5. Correlations occurred between AUDPC and defoliation $(r=0.44$, $P<0.0001)$, AUDPC and yield $(r=-0.37$, $P=0.0002)$, and defoliation and yield $(r=$ $-0.56, P<0.0001)$.

At Pirapo, soybean rust was first observed at GS R2 after the GS R1 fungicide applications were completed. Treatments differed for AUDPC values, and all resulted in lower values than that of the NFC (Table 4). Ten treatments resulted in lower values than all other treatments, and included four single application treatments (PYR, TEB, AZO + PRO, and PYR + TEB) at GS R1. Defoliation differed among treatments, with 16 treatments resulting in less defoliation than the NFC. Six treatments did not differ from the TEB/PYR at GS R1 + R3 treatment that had the least defoliation. Treatments differed for yield, with 19 treatments resulting in higher yields than the NFC. Four treatments did not differ from the treatment with the highest yield (PYR + TEB at GS R1 + R3), and all five of these treatments were multiple applications of fungicides. Correlations occurred between AUDPC and defoliation $(r=0.76, P<$ $0.0001)$, AUDPC and yield $(r=-0.86, P<$ $0.0001)$, and defoliation and yield $(r=$ $-0.81, P<0.0001)$.

At Capitán Meza, soybean rust was first observed at GS R2 after the GS R1 fungicide applications were completed. AUDPC differed among treatments (Table 4). All treatments except for TEB applied at GS $\mathrm{R} 5$ resulted in a lower AUDPC than the NFC. Eighteen treatments were similar to the PYR/TEB at GS R1 + R3 treatment that resulted in an AUDPC value of 5. The four treatments with higher AUDPC values all were single application treatments at GS R5. Defoliation differed among treatments, with all treatments resulting in less defoliation than the NFC. One treatment (TEB/PYR at GS R1 + R3) resulted in less defoliation than all but one other treatment (PYR/TEB at GS R1 + R3). Yield differed among treatments, with 17 resulting in higher yields than the NFC. Nine treatments did not differ in yield from the highest yielding treatment (PYR + TEB at GS $\mathrm{R} 1+\mathrm{R} 3$ ), and all but two were multiple applications. Correlations occurred between AUDPC and defoliation $(r=0.51, P$ $<0.0001)$, AUDPC and yield $(r=-0.47, P$ $<0.0001)$, and defoliation and yield $(r=$ $-0.46, P<0.0001)$.
At Enterprise, soybean rust was first observed at GS R5 after all fungicide applications were completed. AUDPC differed $(P=0.0001)$ among treatments (Table 4). All treatments resulted in a lower AUDPC than the NFC, and 14 did not differ from the lowest AUDPC value of 0 . Of those 14, all but four were multiple applications, and three of those four were applications at GS R3 or GS R5. Defoliation differed among treatments, and five treatments did not differ from the best treatment (PRY + TEB at GS R1 + R3); all were multiple application treatments but one. Yield differed among treatments, with 15 resulting in higher yields than the NFC. Ten treatments did not differ from the highest yielding treatment (TEB at GS R1 + R3 + R5), and all but three treatments were multiple applications. AUDPC and defoliation $(r=0.68, P$
$<0.0001)$, AUDPC and yield $(r=-0.61, P$ $<0.0001)$, and defoliation and yield $(r=$ $-0.61, P<0.0001)$ were correlated.

At Quincy, soybean rust was first observed at GS R5 prior to the GS R5 fungicide applications. AUDPC differed among treatments (Table 4), with all treatments resulting in a lower AUDPC than the NFC. Eight of 11 treatments with the lowest AUDPC had multiple applications. All single applications or PYR and TEB were intermediate. Defoliation differed among treatments, and all but one treatment (AZO + PRO at GS R1) resulted in less defoliation than the NFC. Treatments with multiple applications of TEB and PYR and single applications of TEB, PYR, or TEB + PYR at GS R5 resulted in the lowest defoliation. Yield differed among treatments, with all but three $(\mathrm{AZO}+\mathrm{PRO}$ at

Table 2. Analysis of variance for the area under disease progress curve (AUDPC), defoliation, and yield to control soybean rust in locations with 16 and 24 treatments

\begin{tabular}{|c|c|c|c|c|c|}
\hline Variable & Source of variation & df & Mean square & $F$ value & $P>F$ \\
\hline \multicolumn{6}{|c|}{ Bella Vista, Paraguay 2005} \\
\hline \multirow[t]{2}{*}{ AUDPC } & Block & 3 & 127,505 & 2 & 0.1593 \\
\hline & Treatment & 15 & $18,401,500$ & 52 & $<0.0001$ \\
\hline \multirow{2}{*}{ Defoliation } & Block & 3 & 592 & 5 & 0.0069 \\
\hline & Treatment & 15 & 1,898 & 3 & 0.0026 \\
\hline \multirow[t]{2}{*}{ Yield } & Block & 3 & 159,076 & 1 & 0.3509 \\
\hline & Treatment & 15 & $2,428,658$ & 3 & 0.0007 \\
\hline \multicolumn{6}{|c|}{ Attapulgus, GA 2006} \\
\hline \multirow{2}{*}{ AUDPC } & Block & 3 & 249,333 & 9 & 0.0001 \\
\hline & Treatment & 15 & $2,038,640$ & 14 & $<0.0001$ \\
\hline \multirow[t]{2}{*}{ Defoliation } & Block & 3 & 234 & 1 & 0.592 \\
\hline & Treatment & 15 & 55,061 & 20 & $<0.0001$ \\
\hline \multirow[t]{2}{*}{ Yield } & Block & 3 & $1,758,165$ & 4 & 0.0184 \\
\hline & Treatment & 15 & $6,103,921$ & 3 & 0.0075 \\
\hline \multicolumn{6}{|c|}{ Bella Vista, Paraguay 2006} \\
\hline \multirow{2}{*}{ AUDPC } & Block & 3 & 14,178 & 4 & 0.016 \\
\hline & Treatment & 23 & 315,886 & 11 & $<0.0001$ \\
\hline \multirow[t]{2}{*}{ Defoliation } & Block & 3 & 480 & 4 & 0.0064 \\
\hline & Treatment & 23 & 12,436 & 15 & $<0.0001$ \\
\hline \multirow[t]{2}{*}{ Yield } & Block & 3 & $1,315,804$ & 3 & 0.0583 \\
\hline & Treatment & 23 & $9,551,711$ & 2 & 0.0021 \\
\hline \multicolumn{6}{|c|}{ Pirapo, Paraguay 2006} \\
\hline \multirow[t]{2}{*}{ AUDPC } & Block & 3 & 16,989 & 2 & 0.0933 \\
\hline & Treatment & 23 & $2,653,843$ & 45 & $<0.0001$ \\
\hline \multirow[t]{2}{*}{ Defoliation } & Block & 3 & 592 & 5 & 0.0069 \\
\hline & Treatment & 23 & 1,898 & 3 & 0.0026 \\
\hline \multirow[t]{2}{*}{ Yield } & Block & 3 & 35,994 & 1 & 0.6473 \\
\hline & Treatment & 23 & $14,711,846$ & 30 & $<0.0001$ \\
\hline \multicolumn{6}{|c|}{ Capitán Meza, Paraguay 2006} \\
\hline \multirow[t]{2}{*}{ AUDPC } & Block & 3 & 41,667 & 1 & 0.255 \\
\hline & Treatment & 23 & $1,327,854$ & 6 & $<0.0001$ \\
\hline \multirow[t]{2}{*}{ Defoliation } & Block & 3 & 184 & 2 & 0.2006 \\
\hline & Treatment & 23 & 6,230 & 7 & $<0.0001$ \\
\hline \multirow[t]{2}{*}{ Yield } & Block & 3 & 165,237 & 1 & 0.2536 \\
\hline & Treatment & 23 & $3,170,527$ & 3 & $<0.0001$ \\
\hline \multicolumn{6}{|c|}{ Enterprise, Zimbabwe 2006} \\
\hline AUDPC & Block & 3 & 423,776 & 2 & 0.1256 \\
\hline & Treatment & 23 & $36,400,386$ & 22 & $<0.0001$ \\
\hline Defoliation & Block & 3 & 1,881 & 4 & 0.0105 \\
\hline & Treatment & 23 & 113,893 & 32 & $<0.0001$ \\
\hline Yield & Block & 3 & 37,970 & 0 & 0.9749 \\
\hline & Treatment & 23 & $16,312,326$ & 4 & $<0.0001$ \\
\hline Quincy, FL 2 & & & & & \\
\hline AUDPC & Block & 3 & 42,988 & 2 & 0.2096 \\
\hline & Treatment & 23 & $5,119,869$ & 24 & $<0.0001$ \\
\hline Defoliation & Block & 3 & 1,106 & 6 & 0.0008 \\
\hline & Treatment & 23 & 10,151 & 8 & $<0.0001$ \\
\hline Yield & Block & 3 & 117,217 & 1 & 0.576 \\
\hline & Treatment & 23 & $18,616,842$ & 14 & $<0.0001$ \\
\hline
\end{tabular}


$\mathrm{R} 1, \mathrm{AZO}+\mathrm{PRO}$ at R3, and PYR at R1) resulting in greater yields than the NFC. Multiple applications of TEB and PYR or $\mathrm{TEB}+\mathrm{PYR}$ at GS R3 + R5 and single applications of TEB or TEB + PYR at GS $\mathrm{R} 5$ produced the highest yield. AUDPC and defoliation $(r=0.85, P<0.0001)$, AUDPC and yield $(r=-0.82, P<0.0001)$, and defoliation and yield $(r=-0.71, P<$ 0.0001 ) were correlated.

Soybean rust was observed as early as the GS R2 at two locations, Pirapo and
Capitán Meza, but was observed at or after the GS R5 at Bella Vista, Enterprise, and Quincy. By combining data from Pirapo and Capitán Meza, applications made at GS R1 tended to have the highest yields, followed by the applications made at GS

Table 3. Soybean rust severity, defoliation, and yield from the treatments in the fungicide application timing experiment to control soybean rust in Bella Vista, Paraguay in 2005 and Attapulgus, GA in 2006

\begin{tabular}{|c|c|c|c|c|c|c|c|}
\hline \multicolumn{2}{|c|}{ Treatments } & \multicolumn{3}{|c|}{ Bella Vista } & \multicolumn{3}{|c|}{ Attapulgus } \\
\hline Fungicide $^{\mathbf{a}}$ & Appl. time ${ }^{b}$ & Severity AUDPC $^{c}$ & Def. $^{\text {d }}(\%)$ & Yield (kg/ha) & Severity AUDPC & Def. (\%) & Yield (kg/ha) \\
\hline PYR & $\mathrm{R} 1$ & 806 & 63 & 2,348 & 296 & 90 & 4,149 \\
\hline PYR & R3 & 729 & 65 & 2,217 & 154 & 70 & 4,722 \\
\hline PYR & R5 & 978 & 70 & 2,366 & 133 & 75 & 4,065 \\
\hline TEB & R1 & 177 & 68 & 2,521 & 313 & 68 & 4,517 \\
\hline TEB & R3 & 226 & 73 & 2,256 & 84 & 83 & 4,563 \\
\hline TEB & R5 & 257 & 73 & 2,383 & 132 & 85 & 4,232 \\
\hline $\mathrm{AZO}+\mathrm{PRO}$ & R1 & 1,363 & 78 & 2,160 & 232 & 80 & 4,312 \\
\hline $\mathrm{AZO}+\mathrm{PRO}$ & R3 & 1,238 & 73 & 2,542 & 267 & 78 & 4,466 \\
\hline $\mathrm{AZO}+\mathrm{PRO}$ & R5 & 1,028 & 70 & 2,298 & 280 & 89 & 4,350 \\
\hline $\mathrm{AZO}+\mathrm{PRO}$ & $\mathrm{R} 1+\mathrm{R} 3$ & 988 & 65 & 2,460 & 189 & 68 & 4,698 \\
\hline $\mathrm{AZO}+\mathrm{PRO}$ & $\mathrm{R} 3+\mathrm{R} 5$ & 806 & 68 & 2,517 & 190 & 65 & 4,740 \\
\hline PYR/TEB & $\mathrm{R} 1+\mathrm{R} 3$ & 6 & 63 & 2,152 & 34 & 60 & 4,415 \\
\hline PYR/TEB & $\mathrm{R} 3+\mathrm{R} 5$ & 49 & 68 & 2,261 & 48 & 63 & 4,886 \\
\hline TEB/PYR & $\mathrm{R} 1+\mathrm{R} 3$ & 28 & 63 & 2,520 & 55 & 63 & 4,453 \\
\hline TEB/PYR & $\mathrm{R} 3+\mathrm{R} 5$ & 20 & 65 & 2,345 & 34 & 65 & 4,521 \\
\hline NFC & $\ldots$ & 1,750 & 83 & 1,737 & 786 & 98 & 3,558 \\
\hline $\operatorname{LSD}(P=0$. & & 218 & 9 & 310 & 140 & 10 & 567 \\
\hline
\end{tabular}

${ }^{a}$ PYR = pyraclostrobin (168 g a.i./ha, Headline, BASF Corporation), TEB = tebuconazole (126 g a.i./ha, Folicur, Bayer CropScience), AZO = azoxystrobin + PRO $=$ propiconazole $(127+76 \mathrm{~g}$ a.i./ha, Quilt, Syngenta Crop Protection $)$, and NFC $=$ no fungicide control. Sequential applications are noted as $\mathrm{XXX} / \mathrm{XXX}$, whereas combination products are listed as $\mathrm{XXX}+\mathrm{XXX}$

${ }^{\mathrm{b}}$ Growth stages (GS) of soybean (R1 = beginning flowering, R3 = beginning pod, and R5 = beginning seed), soybean rust was first detected after GS R5 at Bella Vista and after GS R4 at Attapulgus.

${ }^{c}$ Area under disease progress curve (AUDPC) was calculated with three dates of disease severity ratings.

${ }^{d}$ A visual assessment of soybean leaf defoliation was taken on 26 April 2005 at Bella Vista and on 13 October 2006 at Attapulgus.

${ }^{\mathrm{e}}$ Least significant difference.

Table 4. Soybean rust severity, defoliation, and yield for treatments in the fungicide application timing experiment to control soybean rust in Bella Vista, Pirapo, and Capitán Meza, Paraguay; Enterprise, Zimbabwe; and Quincy, FL in 2006

\begin{tabular}{|c|c|c|c|c|c|c|c|c|c|c|c|c|c|c|c|c|}
\hline & & \multicolumn{3}{|c|}{ Bella Vista } & \multicolumn{3}{|c|}{ Pirapo } & \multicolumn{3}{|c|}{ Capitán Meza } & \multicolumn{3}{|c|}{ Enterprise } & \multicolumn{3}{|c|}{ Quincy } \\
\hline \multicolumn{2}{|c|}{ Treatments } & & Def. $^{d}$ & Yield & & Def. & Yield & Sev. & Def. & Yield & & Def. & Yield & & Def. & Yield \\
\hline Fungicide $^{a}$ & Appl. $^{\text {b }}$ & AUDPC $^{\mathrm{c}}$ & $(\%)$ & (kg/ha) & AUDPC & $(\%)$ & (kg/ha) & AUDPC & $(\%)$ & (kg/ha) & AUDPC $^{\mathbf{c}}$ & $(\%)$ & (kg/ha) & AUDPC & $(\%)$ & (kg/ha) \\
\hline PYR & $\mathrm{R} 1$ & 58 & 100 & 2,709 & 58 & 78 & 1,582 & 29 & 81 & 1,758 & 1,513 & 78 & 3,293 & 581 & 76 & 3,231 \\
\hline PYR & R3 & 2 & 69 & 3,252 & 315 & 85 & 1,079 & 51 & 84 & 1,608 & 1,531 & 70 & 3,410 & 306 & 73 & 3,668 \\
\hline PYR & R5 & 73 & 95 & 2,920 & 367 & 96 & 685 & 189 & 90 & 1,535 & 274 & 63 & 3,747 & 312 & 60 & 3,692 \\
\hline TEB & $\mathrm{R} 1$ & 14 & 99 & 2,888 & 19 & 63 & 1,682 & 13 & 83 & 1,634 & 809 & 95 & 3,460 & 572 & 75 & 3,316 \\
\hline TEB & R3 & 2 & 96 & 3,120 & 259 & 88 & 1,216 & 24 & 76 & 1,702 & 784 & 98 & 3,330 & 338 & 63 & 3,852 \\
\hline TEB & R5 & 7 & 95 & 3,145 & 345 & 99 & 757 & 347 & 89 & 1,405 & 949 & 98 & 3,133 & 240 & 60 & 4,038 \\
\hline TEB & $\mathrm{R} 1 / \mathrm{R} 3$ & 3 & 89 & 2,971 & 10 & 46 & 1,637 & 7 & 73 & 1,868 & 293 & 85 & 3,593 & 213 & 63 & 3,808 \\
\hline TEB & R3/R5 & 2 & 92 & 3,457 & 260 & 86 & 1,250 & 32 & 83 & 1,727 & 125 & 84 & 3,623 & 96 & 55 & 4,213 \\
\hline TEB & R1/R3/R5 & 0 & 83 & 3,057 & 10 & 35 & 1,822 & 10 & 75 & 1,760 & 0 & 53 & 4,333 & 57 & 53 & 4,371 \\
\hline $\mathrm{AZO}+\mathrm{PRO}$ & $\mathrm{R} 1$ & 104 & 100 & 3,071 & 64 & 70 & 1,483 & 18 & 83 & 1,674 & 1,559 & 99 & 3,177 & 737 & 89 & 3,056 \\
\hline $\mathrm{AZO}+\mathrm{PRO}$ & $\mathrm{R} 3$ & 53 & 94 & 3,136 & 276 & 83 & 1,290 & 51 & 85 & 1,651 & 1,469 & 98 & 3,200 & 671 & 75 & 3,117 \\
\hline $\mathrm{AZO}+\mathrm{PRO}$ & R5 & 44 & 98 & 2,993 & 434 & 98 & 666 & 247 & 88 & 1,471 & 1,022 & 83 & 3,577 & 496 & 73 & 3,364 \\
\hline $\mathrm{AZO}+\mathrm{PRO}$ & $\mathrm{R} 1 / \mathrm{R} 3$ & 25 & 92 & 2,898 & 56 & 38 & 1,722 & 30 & 73 & 1,750 & 1,313 & 75 & 3,347 & 397 & 73 & 3,228 \\
\hline $\mathrm{AZO+PRO}$ & R3/R5 & 63 & 93 & 3,048 & 213 & 78 & 1,283 & 81 & 89 & 1,605 & 323 & 33 & 4,077 & 372 & 63 & 3,548 \\
\hline PYR+TEB & $\mathrm{R} 1$ & 40 & 94 & 3,213 & 12 & 43 & 1,689 & 10 & 81 & 1,901 & 224 & 8 & 4,027 & 544 & 74 & 3,068 \\
\hline PYR+TEB & R3 & 160 & 100 & 2,672 & 266 & 75 & 1,441 & 72 & 75 & 1,658 & 300 & 43 & 4,023 & 206 & 63 & 3,888 \\
\hline PYR+TEB & R5 & 3 & 93 & 3,155 & 405 & 98 & 770 & 166 & 90 & 1,327 & 125 & 58 & 3,207 & 214 & 60 & 4,166 \\
\hline PYR+TEB & $\mathrm{R} 1 / \mathrm{R} 3$ & 1 & 71 & 3,409 & 8 & 38 & 1,900 & 13 & 75 & 2,016 & 0 & 4 & 4,213 & 135 & 55 & 4,068 \\
\hline PYR+TEB & $\mathrm{R} 3 / \mathrm{R} 5$ & 0 & 64 & 3,959 & 205 & 65 & 1,382 & 51 & 75 & 1,907 & 0 & 6 & 4,037 & 77 & 53 & 4,214 \\
\hline PYR/TEB & $\mathrm{R} 1 / \mathrm{R} 3$ & 0 & 76 & 3,459 & 12 & 30 & 1,844 & 5 & 69 & 1,883 & 261 & 8 & 4,247 & 205 & 63 & 3,946 \\
\hline PYR/TEB & $\mathrm{R} 3 / \mathrm{R} 5$ & 1 & 74 & 3,565 & 286 & 75 & 1,396 & 52 & 84 & 1,701 & 6 & 15 & 4,050 & 106 & 55 & 4,259 \\
\hline TEB/PYR & $\mathrm{R} 1 / \mathrm{R} 3$ & 3 & 69 & 3,173 & 9 & 33 & 1,740 & 6 & 61 & 1,961 & 328 & 25 & 3,893 & 184 & 60 & 3,885 \\
\hline TEB/PYR & R3/R5 & 0 & 80 & 3,814 & 221 & 39 & 1,584 & 45 & 83 & 1,794 & 0 & 19 & 4,023 & 123 & 58 & 4,036 \\
\hline $\mathrm{NFC}$ & $\ldots$ & 237 & 100 & 2,751 & 614 & 100 & 666 & 480 & 100 & 1,341 & 1,988 & 100 & 2,847 & 951 & 90 & 2,841 \\
\hline \multicolumn{2}{|c|}{$\operatorname{LSD}(P=0.05)^{\mathrm{e}}$} & 51 & 8 & 578 & 71 & 16 & 208 & 141 & 9 & 281 & 377 & 18 & 593 & 136 & 11 & 341 \\
\hline
\end{tabular}

${ }^{a}$ PYR = pyraclostrobin $(168 \mathrm{~g}$ a.i./ha, Headline, BASF Corporation $), \mathrm{TEB}=$ tebuconazole $(126 \mathrm{~g}$ a.i./ha, Folicur, Bayer CropScience $), \mathrm{AZO}=$ azoxystrobin + PRO = propiconazole $(127+76 \mathrm{~g}$ a.i./ha, Quilt, Syngenta Crop Protection), and NFC $=$ nonfungicide control. Sequential applications are noted as XXX/XXX, whereas combination products are listed as $\mathrm{XXX}+\mathrm{XXX}$

b Growth stages (GS) of soybean (R1 = beginning flowering, R3 = beginning pod, and R5 = beginning seed), soybean rust was first detected at GS R2 in Pirapo and Capitán Meza, GS R4 at Quincy and after GS R5 in Bella Vista and Enterprise.

${ }^{c}$ Area under disease progress curve (AUDPC) was calculated with three dates of disease severity ratings.

d A visual assessment of soybean leaf defoliation was taken on 6 April 2006 for Bella Vista, 24 May 2006 for Pirapo, 27 April 2006 for Capitán Meza, 3 April for Enterprise, and 5 October 2006 for Quincy.

${ }^{\mathrm{e}}$ Least significant difference. 
R3 (Fig. 1). Applications made at GS R5 were similar to the NFC. In contrast, when data were combined from the three locations where rust was observed at or after GS R5, the highest yields tended to be with applications made at GS R3 and GS $\mathrm{R} 5$, while the lower yields were observed with the GS R1 applications (Fig. 2).

\section{DISCUSSION}

In our study, a growth stage-based program with a single fungicide application at GS R3 was an effective treatment to control soybean rust at most locations, but it was not always among the treatments with the highest yield when soybean rust was first observed during early or late reproductive growth stages. Multiple applications, such as three applications of TEB, resulted in low AUDPC and high yield levels; however, often other treatments that had fewer applications did equally as well when timed near to the onset of rust. For example, at Capitán Meza and Pirapo where rust was first observed just a few days after the first fungicide application, AUDPC, defoliation, and yield did not differ between the PYR + TEB combination applied once at GS R1 and three applications of TEB with the first application at GS R1.

One of the strategies for managing soybean rust is to scout and initiate fungicide application at first detection to reduce the number of fungicide applications and ensure that applications are made when needed. In this study, fungicide applications made 14 to 20 days after first observation of symptoms tended to result in yield levels lower than those observed in treatments made prior to first detection, especially when the rust was observed early in the reproductive stage and fungicide was applied later in the reproductive stages. This trend was most apparent with the single applications of PYR. At Pirapo and Capitán Meza, where soybean rust was first observed at GS R2, the highest yield levels were observed with the GS R1 application. At the remaining locations, soybean rust was first detected after GS R4, and the highest yield levels were observed with the GS R3 and/or GS R5 applications of PYR. Yield levels from the solo applications of $\mathrm{AZO}+\mathrm{PRO}$ followed the pattern observed with PYR. The limiting factor to applying fungicides at first detection is the need for an intensive scouting system that detects the disease soon after initial symptom development. Since yields tended to decrease as the time between first detection and first application increased, recommendations to apply fungicides as a preventative or within a couple of weeks after the first observation were confirmed (10).

A forecast system based on monitoring source regions for urediniospore production and modeling air movement, as was done to predict the geographical extent and timing of soybean rust in 2006 over the Ohio River Valley (9), are useful for determining fungicide applications and will reduce the number of applications from those of a growth-stage-based program.
Once in full practice, such a system will reduce the need for an intensive scouting program. The predictive models, with a decision to apply fungicides ahead of or soon after initial infection, will improve

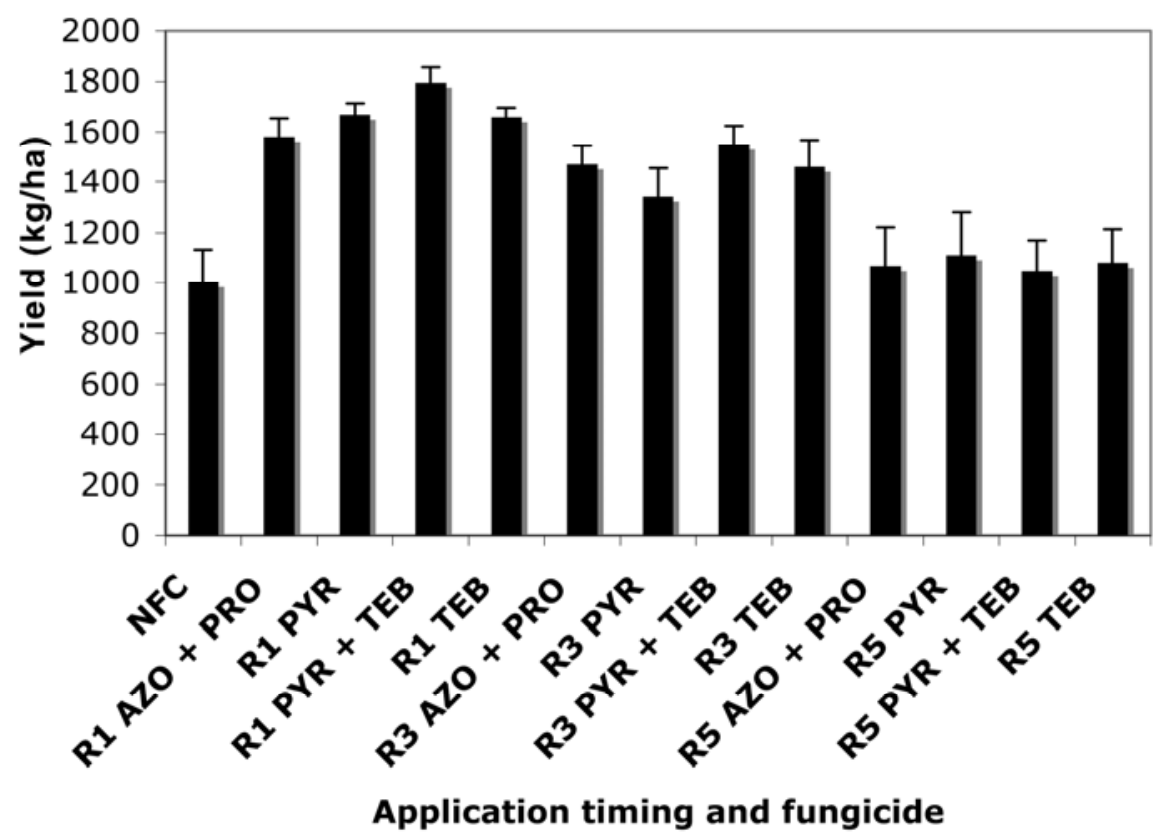

Fig. 1. Mean soybean yields from two locations (Pirapo and Capitán Meza, Paraguay) with detection of soybean rust prior to pod formation in no fungicide control (NFC) plots and plots treated with fungicides PYR $=$ pyraclostrobin $(168 \mathrm{~g}$ a.i./ha, Headline, BASF Corporation $)$, TEB $=$ tebuconazole $(126$ g a.i./ha, Folicur, Bayer CropScience), AZO = azoxystrobin + PRO $=$ propiconazole $(127+76 \mathrm{~g}$ a.i./ha, Quilt, Syngenta Crop Protection), at reproductive (R) growth stages (GS) R1 = beginning flowering, R3 = beginning pod, and R5 = beginning seed. Vertical lines above bars represent standard errors of the mean.

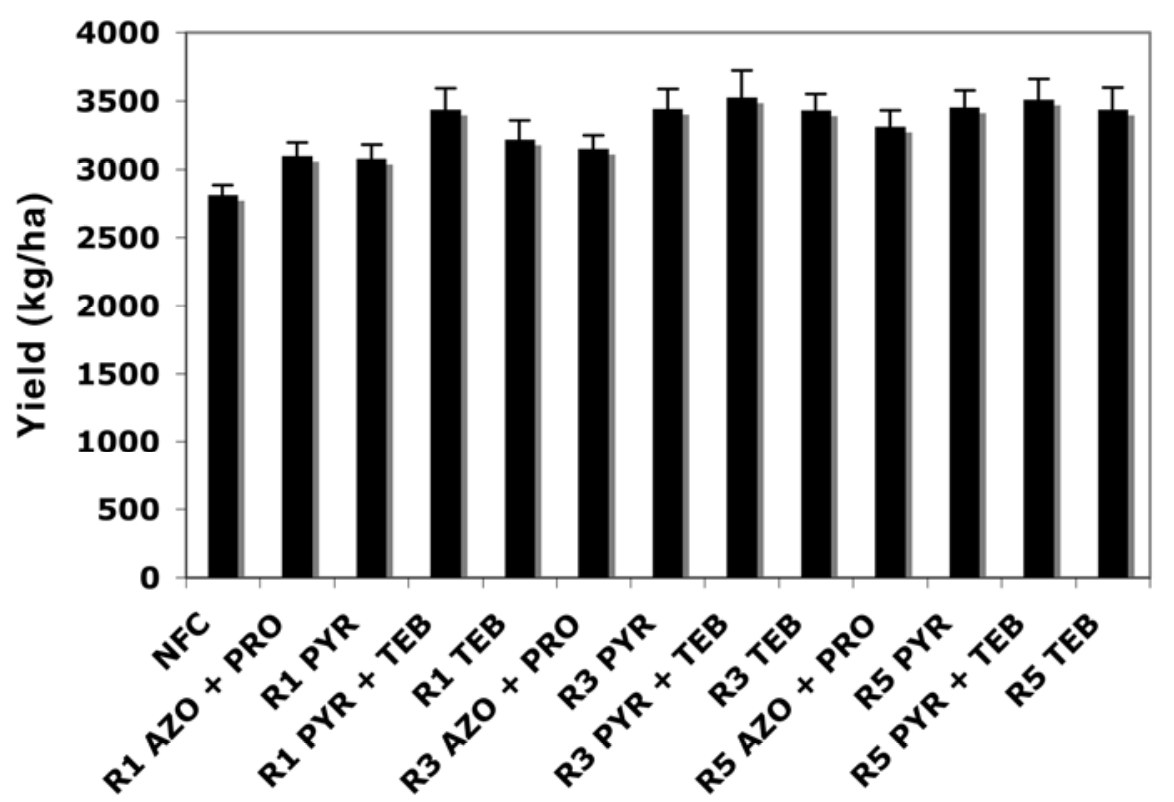

\section{Application timing and fungicide}

Fig. 2. Mean soybean yields from three locations (Bella Vista, Paraguay; Enterprise, Zimbabwe; and Quincy, FL) where soybean rust was detected after beginning of pod formation in no fungicide control (NFC) plots and plots treated with fungicides PYR = pyraclostrobin $(168 \mathrm{~g}$ a.i./ha, Headline, BASF Corporation), TEB = tebuconazole (126 g a.i./ha, Folicur, Bayer CropScience), AZO = azoxystrobin + PRO = propiconazole $(127+76 \mathrm{~g}$ a.i./ha, Quilt, Syngenta Crop Protection), at reproductive (R) growth stages (GS) R1 = beginning flowering, R3 = beginning pod, and R5 = beginning seed. Vertical lines above bars represent standard errors of the mean. 
the effectiveness of the fungicides, allowing them to operate in a preventative or early postinfection situation. In this study, fungicide applications made prior to first detection of soybean rust tended to result in yields greater than those observed in applications made after first detection.

Soybean yields were not reduced significantly when rust severity was low $(8,13)$. Developing associations between rust severity and yield is an important aspect of fine-tuning management recommendations. Not only has leaf area infected by rust been associated with lower yields, but it has also been associated with defoliation $(8,13)$. Leaf severity and defoliation were combined to calculate green leaf area that explained 52 to $85 \%$ of the yield loss in several experiments (8). It is known that defoliation alone during the reproductive stages without rust can reduce yields $(2,7)$. Although premature defoliation may be important in causing yield losses, in a rust epidemic both factors, disease severity of leaves and defoliation, should be considered when studying yield and disease relationships. A recent study that evaluated defoliation during seed fill, or GS R5, reported a 40 to $50 \%$ yield loss when plants had $66 \%$ defoliation during the first 3 weeks of seed fill and less loss when defoliation occurred in the later stages of seed fill. This study concluded that the occurrence of rust at any time during the first half of seed fill would justify protective fungicide applications (3).

In locations with low AUDPC values in the NFC (Bella Vista 2006, Capitán Meza, and Enterprise), few differences in yield were observed among fungicides; however, at locations where the AUDPC values in the NFC were greater (Bella Vista 2005, Attapulgus, Pirapo, and Quincy), TEB and PYR + TEB generally resulted in the lowest disease severity followed by PYR. More severe rust was observed with AZO + PRO when compared with other fungicide treatments, although low yields were observed only when rust severity was high.

The use of fungicide products, application tools, and timing of applications are important aspects of managing soybean rust with fungicides (11). Applications that are too early, too late, or too frequent may not be effective or needed to maximize yield. Disease monitoring is crucial for fungicide recommendations based on field observations as opposed to set schedules based on growth stage of the crop or days after planting. The importance of timing fungicide applications to control soybean rust in the United States is critical for best management practices that protect yield without excessive fungicide applications. From this and other studies (13), it appears that there are a number of effective fungicides and combinations that will provide control of soybean rust; however, more studies are needed to determine if application timing of these fungicides will be altered by regional conditions that could include differences in rust intensity and developmental stages of the crop.

\section{ACKNOWLEDGMENTS}

This research was supported by the Illinois Soybean Association, North Central Soybean Research Program, and the United Soybean Board.

\section{LITERATURE CITED}

1. Akem, C. N. 1995. The effect of timing of fungicide applications on the control of frogeye leaf spot and grain yield on soybeans. Eur. J. Plant Pathol. 101:183-187.

2. Board, J. E., and Harville, B. G. 1998. Lateplanted soybean yield reponse to reproductive source/sink stress. Crop Sci. 38:763-771.

3. Board, J. E., Kumudini, S., and Omielan, J. 2007. Fungicide application for Asian soybean rust during the seed filling period. Presented at the ASA-CSSA-SSSA 2007 Interernational Meeting.

4. Caldwell, P. M., and McLaren, N. W. 2004. Soybean rust research in South Africa. Pages 354-360 in: Proceedings of VII World Soybean Research Conference, IV International Soybean Processing and Utilization Conference, III Congresso Mundial de Soja (Brazilian Soybean Conference). F. Moscardi, C. B. Hoffman-Campo, O. Ferreira Saraiva, P. R. Galerani, F. C. Krzyzanowski, and M. C. CarrãoPanizzi, eds. Emprapa Soybean, Londrina.

5. Delaney, D. P., Lawrence, K. S., Sikora, E. J., Lawence, G. W., Delaney, M. A., and Pegues, M. D. 2007. Efficacy of foliar fungicides for Asian soybean rust disease management and yield enhancement in Alabama. Proc. 2007 National Soybean Rust Symposium online.
6. Fehr, W. R., Caviness, C. E., Burmood, D. T., and Pennington, J. S. 1971. Stage of development descriptions for soybeans, Glycine max (L.) Merr. Crop Sci. 11:929-931.

7. Haile, F. J., Higley, L. G., Specht, J. E., and Spomer, S. M. 1998. Soybean morphology and defoliation tolerance. Agron. J. 90:353-362.

8. Hartman, G. L., Wang, T. C., and Tschanz, A. T. 1991. Soybean rust development and the quantitative relationship between rust severity and soybean yield. Plant Dis. 75:596-600.

9. Isard, S. A., Russo, J. M., and Ariatti, A. 2007. The Integrated Aerobiology Modeling System applied to the spread of soybean rust into the Ohio River valley during September 2006. Aerobiologia 23:271-282.

10. Levy, C. 2005. Epidemiology and chemical control of soybean rust in southern Africa. Plant Dis. 89:669-674.

11. Miles, M. R., Hartman, G. L., and Frederick, R. D. 2003. Soybean rust: Is the U.S. crop at risk? Published online at http://www.apsnet. org/online/feature/rust.

12. Miles, M. R., Hartman, G. L., Levy, C., and Morel, W. 2003. Current status of soybean rust control by fungicides. Pestic. Outlook 14:197200.

13. Miles, M. R., Levy, C., Morel, W., Mueller, T., Steinlage, T., van Rij, N., Frederick, R. D., and Hartman, G. L. 2007. International fungicide efficacy trials for the management of soybean rust. Plant Dis. 91:1450-1458.

14. Mueller, T. A., Miles, M. R., Hartman, G. L., and Kemerait, R. C. 2008. Evaluation of fungicides and fungicide timing for the control of soybean rust, Attapulgus, GA, 2006. Plant Disease Management Reports (online). Report 2:FC086. DOI:10.1094/PDMR02. American Phytopathological Society, St. Paul, MN.

15. Mueller, T. A., Miles, M. R., Hartman, G. L., O'Brien, G. K., Marois, J. J., and Wright, D. L. 2008. Evaluation of fungicides and fungicide timing for the control of soybean rust in northwest Florida, 2006. Plant Disease Management Reports (online). Report 2:FC086. DOI:10.1094/PDMR02. American Phytopathological Society, St. Paul, MN.

16. Shaner, G. E., and Finney, R. E. 1977. The effect of nitrogen fertilization on the expression of slow mildewing resistance in Knox wheat. Phytopathology 67:1051-1056.

17. Wang, T. C., and Hartman, G. L. 1992. Epidemiology of soybean rust and breeding for host resistance. Plant Prot. Bull. (Taiwan) 34:109124.

18. Yorinori, J. T., Paiva, W. M., Frederick, R. D., Costamilan, L. M., Bertagnolli, P. F., Hartman, G. E., Godoy, C. V., and Nunes, J., Jr. 2005 Epidemics of soybean rust (Phakopsora pachyrhizi) in Brazil and Paraguay from 2001 to 2003. Plant Dis. 89:675-677. 